Agata Bałdys-Waligórska, Anna Skalniak, Maciej Kołodziej, Jakub Piątkowski, Anna Sowa-Staszczak Chair and Clinic Of Endocrinology UJCM

\title{
Introduction
}

Based on cancer registries, the risk of second primary malignancies in patients with DTC increases by $30 \%$. In our case report we aimed at understanding the patomechanism of metachronous primary tumours in patients with thyroid cancer.

\section{Thyroid cancer}

In a 71-year old female surgery of nodular goitre (1988), followed by papillary thyroid cancer (pT3NxMx) surgery (2008) and complementary 131-I treatment (2009), were performed. In diagnostic WBS (May 2010) no pathologic 131-I uptake, 0,3 $\mathrm{ml}$ thyroid volume (USG), and no enlargement of lymph nodes were stated. Tg concentration after rhTSH stimulation was $10,7 \mathrm{ng} / \mathrm{ml}$. Consecutive 131-I therapy followed (August 2010). Due to increase in thyroglobulin concentration, WBS was performed (2014), with no pathologic 131-I uptake rhTSH-stimulated TSH $(351,9 \mathrm{uU} / \mathrm{ml})$ and $\mathrm{Tg}(13,8 \mathrm{ng} / \mathrm{ml})$.

\section{Endometrial cancer}

Endometrial cancer (GI-GII), pT1cNxMx, was surgically removed (May 2011), followed by tele- and brachytherapy.

\section{Carcinoma clarocellulare}

In 2012 a small left kidney tumour and a tumour in the lower left lung were seen in her chest CT. Following nephrectomy, clear cell cancer (Fuhrman gradus II) infiltrating the capsula was established. Resection of lower lobe of left lung followed (2013) and found to be endometrial cancer metastasis. The patient underwent chemotherapy (6 paclitaxel and carboplatin cycles, 2013).

\section{Pituitary tumour}

PET/CT showed 18F-FDG accumulation in a large (40x30x45 mm) pituitary tumour (SUVmax 21,7). Laboratory diagnostics of pituitary tumour: $\mathrm{TSH}-0,15 \mu \mathrm{lU} / \mathrm{mL}$ FT4 - 24,9 pmol/L PRL $-902 \mu \mathrm{lU} / \mathrm{L}$ $\mathrm{hGH}-1,5 \mathrm{ng} / \mathrm{ml}$ IGF-1 - 112,0 ng/ml FSH $-21,5 \mathrm{mlU} / \mathrm{ml}$ ACTH - 24,0 pg/ml Cortisol $-17,1 \mu \mathrm{g} / \mathrm{dl}$ at 8.00 am Urine osmolality - $663 \mathrm{mOsm} / \mathrm{kg} \mathrm{H} 20$ Plasma osmolality - $295 \mathrm{mOsm} / \mathrm{kg} \mathrm{H} 20$ A wait-and-watch strategy was suggested by consulting neurosurgeon

No pathologic mutations were found in AIP, MEN1, p53, PTEN and CHEK2 genes.
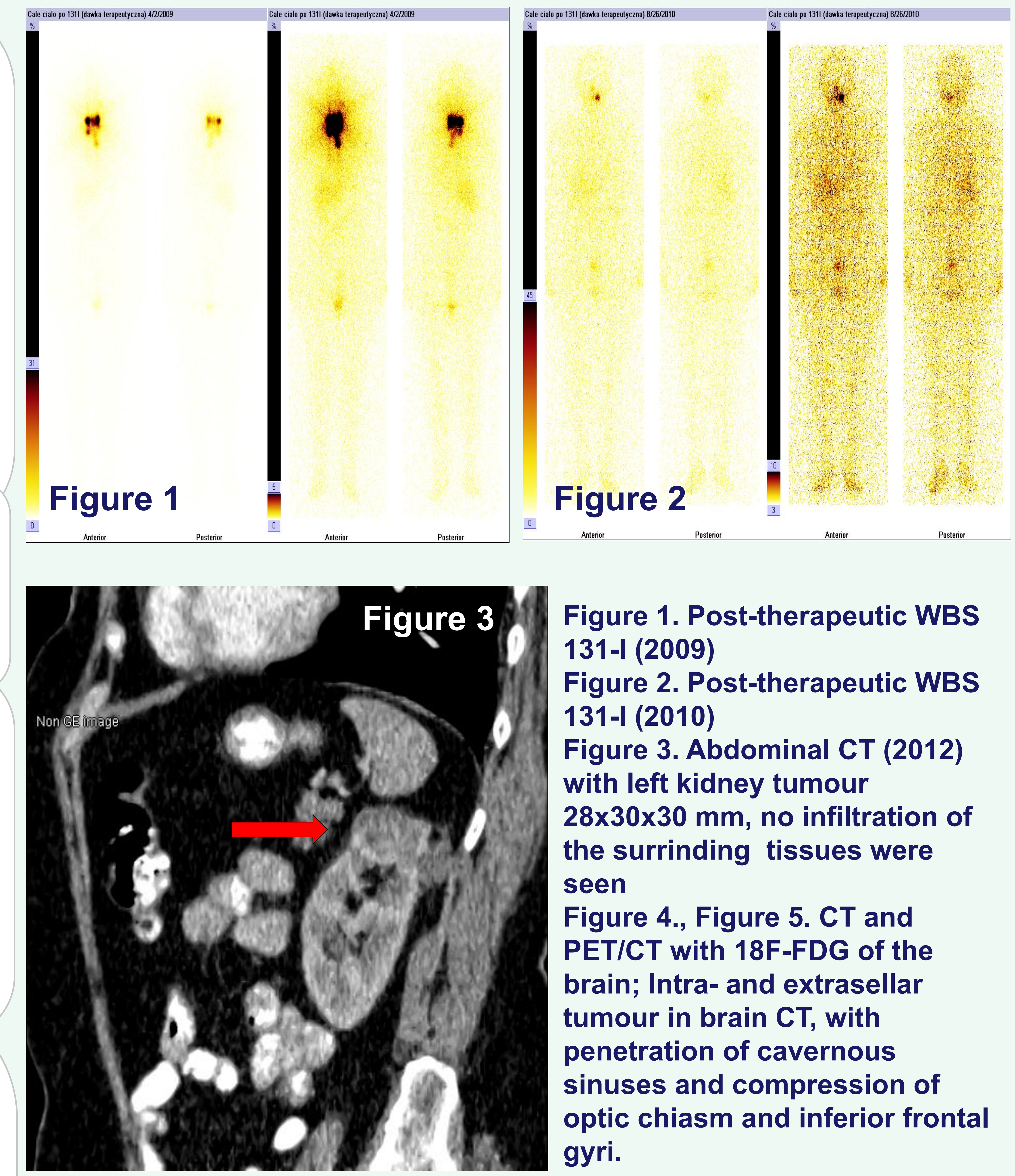

Figure 1. Post-therapeutic WBS 131-I (2009)

Figure 2. Post-therapeutic WBS 131-I (2010)

Figure 3. Abdominal CT (2012) with left kidney tumour $28 \times 30 \times 30 \mathrm{~mm}$, no infiltration of the surrinding tissues were seen

Figure 4., Figure 5. CT and PET/CT with 18F-FDG of the brain; Intra- and extrasellar tumour in brain $\mathrm{CT}$, with penetration of cavernous sinuses and compression of optic chiasm and inferior frontal gyri.

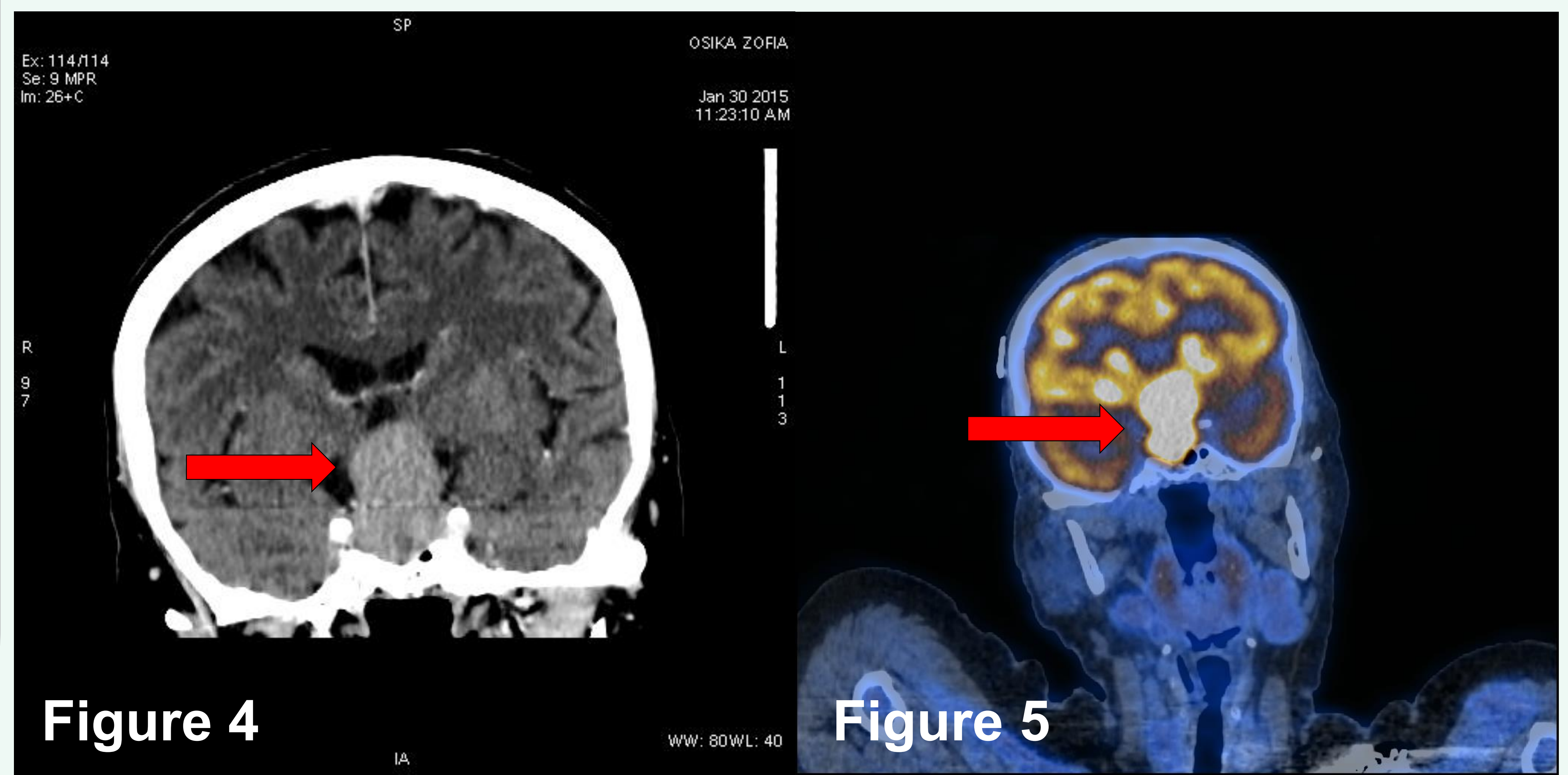

\section{Conclusions}

To elucidate the genetic background of metachronous neoplasms, molecular screening is necessary. Due to possible concurrence of melanoma, breast, prostate or kidney cancer with thyroid cancer, careful screening of the neck of patients with such tumours is recommended. 